\title{
A Review on Ethnopharmacological Applications and Pharmacological Activities of Leea macrophylla
}

\author{
Abdullah AI Faruq ${ }^{1}$, Mohammed Ibrahim ${ }^{1}$, Irin Sultana ${ }^{1}$, and M. Mohi Uddin Chowdhury ${ }^{1}$ \\ ${ }^{1}$ Department of Pharmacy, Southern University Bangladesh, Mehedibag, Chattogram-4000, Bangladesh. \\ *Correspondence: faruq@southern.edu.bd (Abdullah Al Faruq, Lecturer, Department of Pharmacy, Southern University \\ Bangladesh, Mehedibag, Chattogram-4000, Bangladesh).
}

\begin{abstract}
Plants are used as a potential source of medicines since the prehistoric period. Medicinal plants are the richest bio-resource of drugs of a number of traditional systems of medicines. Medicinal plants can also be used as nutraceuticals, food supplements, folk medicines, pharmaceutical intermediates, and chemical entities for synthetic drugs. A good number of researches on medicinal plants have enriched the science of modern medicine over the last decades. Leea macrophylla (Leeaceae) locally known as 'Hastikarna palasa' is a shrub that has been used in herbal medicine as a cure for a number of disorders. Several studies have proven that the plant possesses potential antimicrobial, anti-oxidant, anti-inflammatory, analgesic, neuropharmacological and anti-diabetic activities. Tribal communities used the plant parts as a remedy for a number of ailments as well as nutritional products. Established in-vitro and in-vivo studies were conducted to get evidence of pharmacological activities of the plant parts. This review paper focuses on the phytopharmacological activities and traditional uses of the plant which may help further research activities on L. macrophylla by giving up-to-date information about the plant.
\end{abstract}

Keywords: Leea macrophylla, Traditional uses, Phytochemical overview, and Pharmacological activities.

\section{INTRODUCTION:}

Natural products including plants have been utilized for the ailment of a number of human ailments. Medicinal plants received a great deal of attention for its safest uses and cost consideration. Plants contain numerous bioactive components which is a potential area for research to elevate the scientific knowledge in modern medicine. Phytoconstituents obtained from medicinal plants played a vital role for a cure of various diseases (Islam et al., 2013).

Lead compounds found from medicinal plants possess significant biological and pharmacological activities. About $87 \%$ diseases related to bacterial, fungal infections, cancer and immunological disorders are now a day's treated with drugs from natural products (Mahmud et al., 2011). About five thousands species of higher cryptogams (Plants having no true flowers and seeds) and phanerogams (Plants having special structure for reproduction) have been found in Bangladesh and more than one thousand of these species are reported to have potential medicinal activities. A rich number of therapeutic moieties from plant sources are included in traditional system like Unani, Ayervedic and Homeopathic practices. Evidence from studies have shown in details that medicinal plants used by the traditional practitioners (Herbalists) also exhibit positive pharmacological results during in-vitro and in-vivo tests in laboratories by using different established methods (Hasan et al., 2014).

The goal of the present article is to review the botanical description, distribution, biological and phar- 
macological activities of Leea macrophylla and also highlight its importance as potential candidates for new drugs that may be of value in the treatment and prevention of different ailments.

\section{Origin, Geographical Distribution and Habitat}

Leea macrophylla (Leeaceae) is a wild edible plant with enormous ethomedicinal importance. It is known as 'Hathikana' by the tribal people, literally meaning, having ears like elephant. The plant is an erect shrub or perennial herbs. It may grow up to 90 $\mathrm{cm}$ or even more in height. The plant has switchy branches and perennial swollen roots. They have simple and conspicuously large - lower leaves which can be $60 \mathrm{~cm}$ in diameter. It has tiny greenish white flowers which bloom during July to September in the year (Dewanjee et al., 2013).
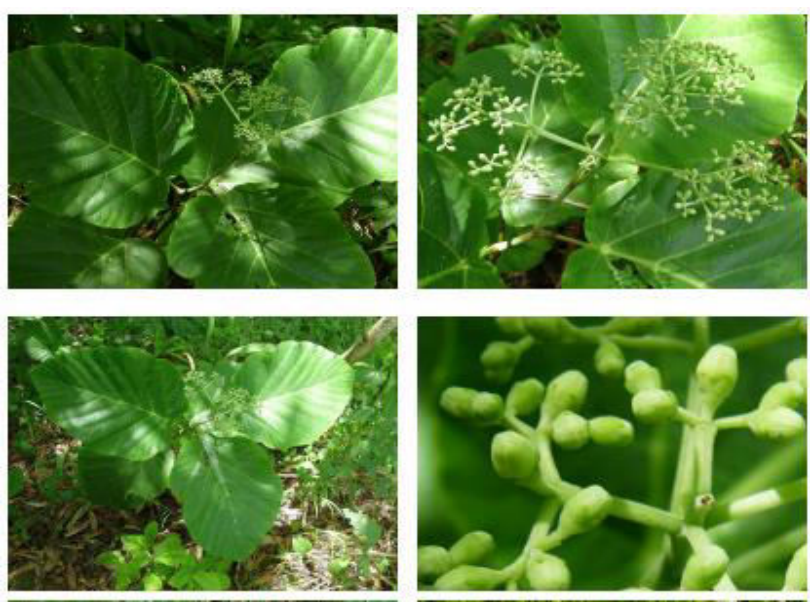

Fig 1: Different plant parts of Leea macrophylla.

The plant mainly grows in moist deciduous and evergreen forests. In Bangladesh, it is located in Dinajpur, Shavar and Chattogram Hill Tracts. It can be found also in Yunnan of China, Cambodia, India, Laos, Myanmar, Nepal and Thailand (web-1 and 2).

\section{Ethnomedical and Traditional Uses}

The plant has various ethnopharmacological uses and almost all parts of the plants possess potential curative properties. Decoction of leaf juice is administers as local anti-inflammatory agent to cure of a number of pain disorders like boils, arthritis, gout and rheumatism. It can be used in cuts and wounds remedy. Like leaves, roots are used in a number of disorders like fracture and cut injury. Roots also possess anthelmintic, astringent, styptic and antiseptic properties. It was reported that the tribal people used the plant parts in cough, cold, headache, body pain and a number of ailments. It has also UniversePG I www.universepg.com significant uses in goiter, gastric tumor, lipoma and tetanus. The tuberous roots are astringent and alexipharmic; traditionally used to kill guinea worm, and pounded is applied to obstinate sores to promote cicatrisation. Plant is also used to heal pain and to stop bleeding (Nijam et al., 2012).

It is also supposed to possess tonic and alterative properties. Traditional practitioners used it to prepare a seasonal tonic called 'Modaka' (Singh and Singh, 1981). Tribal people also use the leaves as vegetables in their food menu. Leaves have hepatoprotective, antiamnesic, and neuroprotective properties. The dried root powders are often mixed with clarified butter to get anti-aging properties. Very recently, it has proved that, the plant contain antioxidant components. Several chemical constituents like phenolics, saponin, glycoside, carbohydrate, and proteins were obtained in the phytochemical studies with the different extracts of seed of L. macrophylla (Rahman et al., 2018).

\section{Phytopharmacological overview of plant extracts}

Antimicrobial Activity - An antimicrobial study was performed by disc diffusion method by using different fractional extracts of the plant parts. The study revealed that n-hexane, chloroform, ethyl acetate and methanol soluble seed fractions of Leea macrophylla exhibited significant inhibition against gram positive bacteria Staphyllococcus aureous. The study has also reported that, all the used extracts were almost inactive against gram negative bacteria like Escherichia coli, Salmonella typhi and Pseudomonas aeruginosa. Ethyl acetate fractions showed highest zone of inhibition among the used extracts (19 mm) (Islam et al., 2013).

Antioxidant Activity - In one study, the ethanol soluble root extract was used as mother extract and fractionated further with organic solvents to evaluate antioxidant activity (Shahen et al., 2019). They performed four methods namely DPPH free radical scavenging assay, superoxide anion radical scavenging, nitric oxide radical scavenging assay and reducing power assay. The study revealed that ethyl acetate soluble fractions exhibited highest radical scavenging activity (Mahmud et al., 2017).

Inhibition of Hepatic Damage - L. macrophylla has protective role on $\mathrm{CCl}_{4}$-induced acute liver injury in rats. Liver damage causes significant increases of total protein and CK-MB in hepatic tissues. Treat- 
ment of L. macrophylla significantly restored the increased level of total protein and CK-MB. The study also suggested that the plant has potential activity to restore CHL, LDH and LDL level (Akhter et al., 2015).

Neuropharmacological Activity - Ferdousy et al. (2016) had found methanol extract was found to show significant $(\mathrm{p}<0.05)$ reduction in movement of mice in dose dependant manner. In the study, $L$. macrophylla root methanol extract was assessed by open field test, hole cross test, elevated plus maze test and thiopental sodium induced sleeping time test for screening neuropharmacological effect on experimental animal. The plant extracts significantly increases sleep time and exhibited CNS depressant activity (Sharif et al., 2019; Ferdousy et al., 2017).

Analgesic Activity - Acidic acid induced writhing method in mice was performed in a study to evaluate plants activity against analgesia. The study revealed that ethanol soluble fractions at the dose of 200 $\mathrm{mg} / \mathrm{kg}$ body weight significantly reduced the number of writhing count with $62.37 \%$ of inhibition when compared to the positive control group diclofenac sodium $(p<0.001)$.

Brine Shrimp Lethality Bioassay - Brine shrimp lethality assay evaluate the killing ability of brine shrimp by the different extracts of plant parts at various doses. In one study, crude ethanol extracts and its various fractionated solvent parts were dissolved in DMSO to get stock solution. The study revealed that, the $\mathrm{LC}_{50}$ values of the ethanolic extract and carbon tetrachloride, chloroform and ethyl acetate soluble fractions were found to be $2.39,0.049,4.53$ and $0.09 \mathrm{~g} / \mathrm{ml}$, respectively which were comparable to the standard vincristine sulphate, (LC50: $0.34 \mathrm{~g}$ / $\mathrm{ml})$. The result of the study suggested the preliminary cytotoxic activity of the plant extract.

Anti-diabetic Activity - A research was conducted to investigate the protective effects of Leea macrophylla Roxb polyphenols on streptozotocin-induced diabetic rats. The study had shown that, Food and fluid intake, weekly blood glucose level, liver glycolgen, aspartate transaminase (AST), creatinine kinase $(\mathrm{CK})$, cholesterol, and lactate dehydrogenase (LDH) were significantly decreased, whereas oral glucose tolerance (OGTT) ability, serum insulin concentration, and pancreatic islets morphology were significantly improved in the treatment group where plant extract had been administered compared to the control group. The study revealed that, L. macrophylla can exert a potential effort to restore pancreatic $\beta$-cell damaged by streptozotocin induction.

Anti-inflammatory and Anti-pyretic Activity - A study has shown the potential of anti-inflammatory activity of methanol extract of $L$. macrophylla leaves. The result of the study showed that, methanol extract inhibited lipopolysaccharide stimulated production of inflammatory mediators viz. prostaglandin E2, tumor necrotic factor- $\alpha$, interleukin- 6 and interleukin- $1 \beta$ in vitro in mouse peritoneal macrophages. The researchers also performed in vivo anti-inflammatory activity test of this extract by using carrageenan induced paw edema and cotton pellet granuloma assays in experimental rats. They reported, oral administration of extract (100 and $200 \mathrm{mg} / \mathrm{kg}$ ) exhibited dose dependant inhibition of carrageenan induced inflammation $(p<0.05)$ and the reduction of the granuloma tissue formation $(p<$ $0.05-0.01)$. It is found that, treatment with extract (100 and $200 \mathrm{mg} / \mathrm{kg}$, orally) significantly reduced the yeast provoked elevated body temperature $(p<0.05-0.01)$ in experimental rats which is the evidence of anti-pyretic activity of the plant extracts (Dewanjee et al., 2014).

\section{CONCLUSION:}

The review summarized the updated information related to the potential phytochemical and pharmacological activities of a traditionally used plant Leea macrophylla which belongs to the plant family Leeaceae. Traditionally the plant parts are used to heal a number of ailments like cough, common cold, local pain, rheumatism, goiter, headache etc. On the basis of these traditional uses, a number of scientific studies were performed and they revealed potential activities of the plant species like anti-oxidant, antimicrobials, analgesic, antidiabetics, neuropharmacologicals etc. This review will be useful for further studies on this plant. More research is needed to isolate and characterize bioactive constituents and establish clinical studies to explore the potential uses of Leea macrophylla that may contribute to newer drug development.

\section{ACKNOWLEDGEMENT:}

The authors wish to thank gratefully the authority of Southern University Bangladesh, Chattogram-4000. 


\section{CONFLICTS OF INTEREST:}

The authors declared that they have no competing conflict of interests to publish under current issue of the journal.

\section{REFERENCES:}

1. Akhter, S., Aklima, J., Hasan, M. R. and J. M. Chowdhury, K. H., (2015). Antioxidative Role of Hatikana (Leea macrophylla Roxb.) Partially Improves the Hepatic Damage Induced by $\mathrm{CCl}_{4}$ in Wistar Albino Rats, BioMed Research International, Article ID 356729. https://doi.org/10.1155/2015/356729

2. Dewanjee, S., Dua, T. K. and Sahu, R., (2013). Potential anti-inflammatory effect of Leea macrophylla Roxb. leaves: A wild edible plant, Food and Chemical Toxicology, 59, 514-520.

3. Ferdousy, S., Rahman, M.A., Al-Amin, M. M. et al. (2017). Antioxidative and neuroprotective effects of Leea macrophylla methanol root extracts on diazepam-induced memory impairment in amnesic Wistar albino rat, Clin Phytosci 2(17). https://doi.org/10.1186/s40816-016-0031-6

4. Hasan, M.M., Ali, M. A. and Alamgir, A.N.M. (2014). Medicinal plant diversity in Chittagong, Bangladesh: A database of 100 medicinal plants, Journal of Scientific and Innovative Research, 3(5): 500-514.

5. Islam, M. B., Sarkar, M. Z., Jalil, M. A., and Amin, R., (2013). Phytochemical Screening and Anti-microbial Activity Studies on Leea macrophylla Seed Extracts, J. Sci. Res. 5(2), 399-405. https://doi.org/10.3329/jsr.v5i2.13213

6. Mahmud, Z.A., Bachar, S. C., and Qais, N., (2011). Evaluation of Anti-nociceptive Activity and Brine shrimp Lethality Bioassay of Roots of Leea macrophylla Roxb, International J. of Pharma Sciences and Research, 2(12): 3230-3234.

http://dx.doi.org/10.13040/IJPSR.0975-8232.2

(12).3230-34
7. Nizam, A. N., Ahmed, N. U. and Islam, M. S., (2012). Whole Leea macrophylla ethanolic extract normalizes kidney deposits and recovers renal impairments in an ethylene glycol-induced urolithiasis model of rats. Asian Pacific J. of Tropical Medicine, 533-538. https://cyberleninka.org/article/n/1160354

8. Rahman, M. A., Aklima, J. and Azadi, M. A., (2018). Leea macrophylla Roxb. leaf extract potentially helps normalize islet of $\beta$-cells damaged in STZ-induced albino rats, Food Sci Nutr, 6: 943-952. https://doi.org/10.1002/fsn3.625

9. Shahen MZ, Uddin ME and Alam MS. (2019). Effect of antibiotic susceptibility and inhibitory activity for the control of growth and survival of microorganisms of extracts of $C$. officinalis, Eur. J. Med. Health Sci. 1(1), 1-9. https://doi.org/10.34104/ejmhs.0190109

10. Sharif IH, Haque MA, Jamal MAHM, and Uddin ME. (2019). Assessment and biomonitoring of the effect of rapeseeds oil on wister rat organs. Am. J. Pure Appl. Sci., 1(4), 20-29. https://doi.org/10.34104/ajpab.019.0192029

11. Singh, R.S. and Singh, A.N., (1981). On the identity and economic medicinal uses of Hastikarna Palasa (Leea macrophylla Roxb., Family: Ampelidaceae) as evidence in the ancient (Sankskrit) texts and traditions. Indian Journal of History of Science, 16(2): 219-222. https://pubmed.ncbi.nlm.nih.gov/11611447/

12. Web-1: Large-Leaf Leea; Leea macrophylla, Identification credit: Dinesh Valke, Photographed in Maharashtra, Accessed 5 May, 2021. http://www.flowersofindia.net/catalog/slides/Hat hikana.html

13. Web-2: keralaplants.in; Leea macrophylla, Accessed 7 May, 2021. http://keralaplants.in/keralaplantsdetails.aspx?id =Leea macrophylla

Citation: Faruq AA, Ibrahim M, Sultana I, and Chowdhury MMU. (2021). A review on ethnopharmacological applications and pharmacological activities of Leea macrophylla, Eur. J. Med. Health Sci., 3(3), 58-61. https://doi.org/10.34104/ejmhs.021.058061 @) (D) 